\title{
Acceptability of COL-1492, a vaginal gel, among sex workers in one Asian and three African cities
}

\author{
A Vandebosch, E Goetghebeur, G Ramjee, M Alary, V Ettiègne-Traoré, V Chandeying, L Van \\ Damme, on behalf of the COL-1492 Study Group
}

Sex Transm Infect 2004;80:241-243. doi: 10.1136/sti.2003.005934

\begin{abstract}
Objectives: To evaluate the acceptability of COL-1492, a vaginal gel containing $52.5 \mathrm{mg}$ nonoxynol-9, in an HIV prevention trial.

Methods: Sex workers participating in a phase II/III triple blind, randomised trial in Benin, Côte d'Ivoire, South Africa, and Thailand were interviewed on the gel's acceptability at monthly scheduled clinic visits. Safer sex counselling, male condoms, and study gels were given at each monthly visit; a gynaecological examination and HIV test were performed. Phase III interviews considered the participants' appreciation of the gel. On the first, second, and fifth follow up visits, the study volunteers completed more extensive questionnaires. Results: Responses were similar between treatment arms. Women indicated not liking their gel in $1.8 \%$ of the visits; $98.1 \%$ of the women found the gel easy to apply; $30.1 \%$ said that it affected sexual intercourse. These effects were mostly improvements $(92.6 \%)$ by facilitating intercourse $(73.6 \%)$. Intercourse was more often affected in women reporting painful sexual intercourse (OR: 2.59 (95\% $\mathrm{Cl} 1.63$ to 4.12$)$ ) and in older women. The latter effect differed among centres. Conclusion: Most participants found their assigned gel acceptable and the vast majority of reported effects on intercourse were favourable. The type of gel had no significant impact on the findings.
\end{abstract}

W hile male condoms provide high levels of protection against HIV and other sexually transmitted infections (STIs), negotiating their use can be difficult for women; hence an urgent need for female controlled methods for HIV prevention. Most research in this area has studied the potential effect of vaginal gels. To be effective in real life these gels must be acceptable. Evidence of acceptability in long term use was therefore collected in a randomised blinded phase II/III trial assessing the effect on HIV transmission of a nonoxynol-9 containing gel, COL-1492, compared with a placebo gel. ${ }^{1}$ This paper reports acceptability findings in phase III.

\section{METHODS}

Data came from the phase III portion of a phase II/III, multicentre, placebo controlled, triple blind study of COL1492 (Advantage S, Columbia Laboratories, New York, NY, USA), a marketed vaginal spermicide containing $52.5 \mathrm{mg}$ nonoxynol-9. The placebo was Replens (polycarbophil, Columbia Laboratories, Paris, France), a marketed vaginal moisturiser. Both gels were similar, except COL-1492 contained 3.5\% nonoxynol-9 and less carbomer. They were packaged in identical single use, disposable applicators, delivering $1.5 \mathrm{ml}$. Study participants were healthy, HIV-1 negative female sex workers in Abidjan, Côte d'Ivoire;
Cotonou, Benin; Durban, South Africa; and Hat Yai, Thailand. ${ }^{1}$ The study was approved by all relevant ethics review committees.

Phase III was initiated in August 1997. At monthly scheduled visits women received safer sex counselling, male condoms, and prefilled applicators. They had a gynaecological examination, HIV and STI tests, and free treatment for any curable STI. At each visit, participants answered standardised questions regarding acceptability of their assigned product. They rated the gel (very unpleasant, unpleasant, acceptable, pleasant) and indicated whether their (paying) clients and (non-paying) partners complained (never, rarely, often, always). On the first, second, and fifth follow up visits women answered a more detailed questionnaire. Answers were dichotomised and explained by treatment group or other covariates, correcting for centre, using marginal logistic regression with an independent working correlation matrix. ${ }^{2}$ Covariate selection followed a two step procedure. First backward elimination was performed in each centre separately, with $\mathrm{p}$ value for removal 5\%. ${ }^{3}$ To facilitate direct comparisons across centres, a common GEE model retained all covariates significant in at least three centres.

The study ended in June 2000 with a significantly higher HIV incidence of 14.7 per 100 person years among COL-1492 users $v 10.3$ per 100 person years among placebo users. ${ }^{1}$

\section{RESULTS}

In all, 764 women were randomised in centres which continued into phase III; 97 had no follow up data and nine in Durban dropped out (three) or seroconverted (six) before the start of phase III, leaving 658 women in this analysis (table 1). Women lost to follow up were significantly younger (with a shorter history as sex worker). In phase III, participants reported 469439 vaginal coital acts with clients, of which $70.9 \%$ involved use of a condom plus study gel, $17.4 \%$ condom only, $9.0 \%$ gel only, and $2.7 \%$ neither gel nor condom. Participants reported 61180 vaginal coital acts with non-paying partners, $38.2 \%$ with condom plus study gel, $6.8 \%$ condom only, $32.0 \%$ gel only, and $23.0 \%$ neither gel nor condom. In total, 1694 visits were considered (table 1). Acceptability answers were similar between treatment arms except for the proportion of visits at which women reported informing their partners of their gel. As this $\mathrm{p}$ value still exceeded $0.83 \%$, the Bonferroni corrected boundary, treatments were pooled in further analyses (table 2).

The percentage of visits where women reported not liking the gel differed significantly between centres (exact p value $<0.01$ ), with the highest percentage in Abidjan and the lowest in Durban (table 2).

Approximately one third of responses indicated that the assigned gel affected sexual intercourse favourably (table 2), mostly because it involved "less pain during intercourse, good lubrication, and facilitated intercourse," except in Durban, where this accounted for just $13.4 \%$ of the answers 
Table 1 Number of women attending the first, second, and fifth follow up visits during phase III

\begin{tabular}{lllllll}
\hline & $\begin{array}{l}\text { No of women } \\
\text { admitted }\end{array}$ & $\begin{array}{l}\text { Dropped out } \\
\text { before visit } \mathbf{1}\end{array}$ & $\begin{array}{l}\text { No of women analysed } \\
\text { (Act/Plac) }\end{array}$ & Visit 1 & Visit 2 & Visit 5 \\
\hline Abidjan & 188 & 26 & $78 / 84$ & 162 & 149 & 86 \\
Cotonou & 259 & 56 & $100 / 103$ & 203 & 186 & 138 \\
Durban & 192 & $5(+9)^{*}$ & $89 / 89$ & 178 & 162 & 137 \\
Hat Yai & 125 & 10 & $56 / 59$ & 115 & 105 & 73 \\
Total & 764 & $97(+9)^{*}$ & $323 / 335$ & 658 & 602 & 477 \\
\hline
\end{tabular}

*In Durban 5 women dropped out at onset of the trial, an additional 9 dropped out (3) or seroconverted (6) before the phase III part.

(table 2). When asked what one liked most about the gel, 40$50 \%$ of answers involved good lubrication, less painful, and facilitated intercourse. Again, Durban differed, with approximately half of the responses indicating that prevention of STIs, including HIV and/or illness, was what they liked most.

In a model explaining any reported effect on sexual intercourse by age at entry, painful sexual intercourse, calendar time, and the method of collecting compliance data, we found a significant interaction with centre for all covariate effects, except for painful sexual intercourse. The adjusted odds of a perceived effect on sexual intercourse was higher for older women in Abidjan $(\mathrm{OR}=1.06$ per yearly increase in age, $95 \%$ CI 1.01 to 1.11) and in Durban $(\mathrm{OR}=1.07,95 \%$ CI 1.02 to 1.12$)$. Furthermore, we saw a significantly higher reported effect on intercourse when women reported painful intercourse in Cotonou $(\mathrm{OR}=3.55$, 95\% CI 1.55 to 8.13 ), Durban (OR $=1.90,95 \%$ CI 1.00 to $3.60)$, Hat Yai (OR $=4.82,95 \%$ CI 1.16 to 20.02$)$, but not in Abidjan (OR $=1.96,95 \%$ CI 0.15 to 25.51$)$. Reports of effects on intercourse increased significantly with time on the study in Durban $(p=0.002)$, but not in the other centres.

Participants reported in $38.8 \%(41.9 \%)$ of the visits informing clients (partners) of their product use. At most visits women reported willingness to continue gel use if it were available after the study (table 2 ).

\section{DISCUSSION}

On most visits, women reported that they liked the gel and would continue its use if available after the trial. This is consistent with the conclusion drawn by Pool et al that women may use any particular product if the choice is limited. Since this was a phase III trial, there was no other formulation available for comparison. As in other trials, ${ }^{4-6}$ improved intercourse, mainly through increased lubrication, was a main reason for liking the product. This suggests that use will increase with increased sexual comfort. This is important since the acceptability of gels is often questioned in cultures where a dry vagina is the norm for sexual intercourse-for example, in Durban. ${ }^{7}$

In Durban, half of the time HIV/STI prevention was named as the best liked feature of the gel, despite monthly intensive safer sex counselling and regular reminders of study information. Similarly, Coggins et $a l^{8}$ found that $40 \%$ of women stated using a product to prevent STIs and another $44 \%$ for dual protection (against both STIs and pregnancy).

In our trial, participants reported informing their sex partners about gel use in approximately $40 \%$ of visits, less often than in a multinational preference study, ${ }^{8}$ where $75 \%$ of women informed their regular partners. This difference may stem from a different study population, women from the general population versus sex workers.

We found substantially fewer acts with reported gel and condom use with partners than with clients. On the other hand, the proportion of acts with gel alone was higher among partners. This points to the importance of a female controlled method for sex with (non-paying) partners which would also apply to the general population where women often risk infection as a result of their partner's behaviour.

As in all behavioural research, our results need cautious interpretation because women may aim to please, especially in direct interviews.

Ninety seven women did not return for any follow up. We ignore their reasons, which may have been product related. Thus, the reported results may overestimate the true

Table 2 Key acceptability items on the first, second, and fifth follow up visits during phase III, by centre

\begin{tabular}{|c|c|c|c|c|c|}
\hline & Abidjan & Cotonou & Durban & Hat Yai & Total \\
\hline \multicolumn{6}{|l|}{ Gel not liked } \\
\hline$\%$ of visits* & 4.5 & 1.3 & 0.2 & 1.7 & 1.8 \\
\hline \multicolumn{6}{|l|}{ Gel easy to apply } \\
\hline \multirow{2}{*}{\multicolumn{6}{|c|}{ Would like to continue to use the gel }} \\
\hline & & & & & \\
\hline$\%$ of visits* ${ }^{*}$ & 87.7 & 91.5 & 81.8 & 52.6 & 81.1 \\
\hline \multicolumn{6}{|l|}{ Gel affected intercourse } \\
\hline$\%$ (n) affectingt & $24.3(379)$ & $41.4(486)$ & $18.2(406)$ & $35.8(288)$ & $30.1(1559)$ \\
\hline$\%$ (n) of affecting reporting improvementł & 96.7 (92) & $95.5(201)$ & $90.5(74)$ & 84.5 (103) & $92.6(470)$ \\
\hline \multicolumn{6}{|l|}{ Why improved intercourse } \\
\hline $\begin{array}{l}\% \text { (n) facilitating intercourse, causing no pain, and } \\
\text { lubricating well }\end{array}$ & $69.7(89)$ & 93.8 (192) & $13.4(67)$ & $80.0(80)$ & $73.6(428)$ \\
\hline \multicolumn{6}{|l|}{ What liked most about gel } \\
\hline$\%$ (n) facilitated intercourse, no pain, and lubrication $†$ & $41.6(375)$ & $49.0(490)$ & $2.2(405)$ & $40.0(270)$ & $33.3(1540)$ \\
\hline$\%$ prevention of STIs and other illness, including HIV $\dagger$ & 5.1 & 22.5 & 53.6 & 7.8 & 23.8 \\
\hline \multicolumn{6}{|l|}{ Informed clients } \\
\hline$\%$ of visits & 50.9 & 53.5 & 23.1 & 21.8 & 38.8 \\
\hline \multicolumn{6}{|l|}{ Informed partners } \\
\hline$\%$ of visits & 53.9 & 45.2 & 40.7 & 21.8 & 41.9 \\
\hline
\end{tabular}


acceptability since women staying in the study were more likely to have liked the gel. The difference between acceptability results obtained in trials $v$ real life has been raised in a previous trial. ${ }^{5}$

In conclusion, our study showed that a small volume of gel was acceptable to most participants. Understanding the factors determining a product's acceptability and thus its use is critically important since a product can only be effective when used regularly. However, not until an effective microbicide for HIV/STI prevention enters the market, can real life acceptability be assessed.

\section{ACKNOWLEDGEMENTS}

Support for this study was provided by the Joint United Nations Programme on HIV/AIDS (UNAIDS) and Columbia Laboratories. The authors thank the study participants, all the staff and monitors in the study centres, and Tina Habash of CONRAD for revising the manuscript.

The COL-1492 study group: Institute of Tropical Medicine, Antwerp, Belgium: Marie Laga; Medical Research Council, Durban, RSA: Salim Abdool Karim, Neetha Morar; Projet SIDA 2, Cotonou, Benin: Léonard Mukenge-Tshibaka, Nassirou Geraldo, Olga Jimaja, Odette Azonnadou; Projet RETRO-CI, Abidjan, Côte d'Ivoire: Peter Ghys, Mamadou Diallo, Camille Anoma, Bea Vuylsteke; Faculty of Medicine, Prince of Songkla University, Hat Yai, Thailand: Jintana Pradutkanchana, Warapon Boonya, Patjanat Jornkrajag, Vipavadee Boonrit; Groupe de recherche en épidémiologie, Université Laval Québec, Canada: Benoît Mâsse, Lucie Ross, Claudia Coté, Caroline Pelletier, Marie-Claude Lambert, Lissa Cormier, Myrto Mondor.

Preliminary results of this analysis were presented at the Microbicides 2002 conference, 12-15 May, Antwerp, Belgium.

\section{CONTRIBUTORS}

AV was involved in data analysis, writing of the manuscript, and performed statistical computing; EG was involved in data analysis and writing of the manuscript; GR, VC, MA, and VET were involved in the data collection and revision of the manuscript; LVD was involved in data analysis, writing of the manuscript, and was the overall study coordinator of the COL-1492 trial.

\section{Authors' affiliations}

A Vandebosch, E Goetghebeur, Ghent University, Ghent, Belgium

G Ramjee, Medical Research Council, Durban, South Africa

M Alary, Population Health Research Unit, Centre Hospitalier Affilié

Universitaire de Québec and Laval University, Québec, Canada

V Ettiègne-Traoré, Projet RETRO-Cl, Abidjan, Côte d'Ivoire

V Chandeying, Faculty of Medicine, Prince of Songkla University, Hat

Yai, Thailand

L Van Damme, CONRAD, Arlington, VA, USA

Correspondence to: Dr Lut Van Damme, CONRAD, 1611 North Kent

Street, Suite 806, Arlington, VA, 22209, USA; lvandamme@conrad.org

Accepted for publication 21 October 2003

\section{REFERENCES}

1 Van Damme L, Ramjee G, Alary M, et al. Effectiveness of COL-1492, a nonoxynol-9 vaginal gel, on HIV-1 transmission in female sex workers: a randomised controlled trial. Lancet

2002;360:971-7.

2 Liang KY, Zeger SL. Longitudinal data analysis using generalised linear models. Biometrika 1986;73:13-22.

3 Fahrmeir L, Tutz G. Multivariate statistical modeling based on a generalised linear model. New York: Springer, 1994:1-512.

4 Pool R, Whitworth JA, Green G, et al. An acceptability study of femalecontrolled methods of protection against HIV and STDs in south-western Uganda. Int J STD AIDS 2000;11:162-7.

5 Coggins C, Blanchard K, Alvarez F, et al. Preliminary safety and acceptability of a carrageenan gel for possible use as a vaginal microbicide. Sex Transm Infect 2000;76:480-3

6 Bentley ME, Morrow KM, Fullem A, et al. Acceptability of a novel vaginal microbicide during a safety trial among low-risk women. Fam Plann Perspect 2000;32:184-8.

7 Ramiee G, Abdool Karim SS, Morar N, et al. Acceptability of a vaginal microbicide among female sex workers. S Afr Med J 1999:89:673-6.

8 Coggins C, Elias CJ, Atisook R, et al. Women's preference regarding the formulation of over-the-counter vaginal spermicides (correspondence). AIDS 1998; 12:1389-91. 